\title{
Gramática Discursivo-Funcional, gramaticalização e modalização ${ }^{1}$
}

\section{Functional Discourse grammar, Grammaticalization, modalization}

\author{
Cibele Naidhig de Souza \\ Universidade Federal Rural do Semi-Árido, Caraúbas, Rio Grande do Norte / Brasil. \\ cibele.naidhig@ufersa.edu.br
}

Resumo: O trabalho investiga encaminhamentos de gramaticalização em usos modais do verbo dar, no português brasileiro contemporâneo. A pesquisa serve-se de dois corpora de língua falada, o C-ORAL BRASIL e o corpus mínimo do NURC (Norma Urbana Culta). A Gramática Discursivo-Funcional, GDF (HENGEVELD; MACKENZIE, 2008), suporte teórico-metodológico, contempla quatro níveis gramaticais (interpessoal, representacional, morfossintático e fonológico), organizados em ordem descendente. Cada um dos níveis apresenta camadas hierarquicamente estruturadas, que permitem identificar a expansão de escopos nos usos modais de dar, em direção ao nível discursivo da língua. A análise sugere um processo de mudança gramatical, cujo trajeto parte de formas plenas do verbo, que se desenvolvem em formas quase auxiliares e construções avulsas do discurso. Tal hipótese de desenvolvimento é compatível com propostas de percursos gramaticais de mudança semântica e formal no modelo da GDF (HENGEVELD,

\footnotetext{
${ }^{1} \mathrm{O}$ presente trabalho foi realizado com apoio do CNPq, Conselho Nacional de Desenvolvimento Científico e Tecnológico - Brasil (pós-doutorado realizado no Departamento de Estudos Linguísticos e Literários do Instituto de Biociências, Letras e Ciências Exatas, UNESP, São José do Rio Preto, São José do Rio Preto, São Paulo, Brasil).
} 
2017) e, ainda, com outros estudos sobre desenvolvimentos no campo modal (BYBEE et al., 1994; TRAUGOTT; DASHER, 2002), entendidos como próprios de gramaticalização.

Palavras-chave: Gramática Discursivo-Funcional; gramaticalização; modalidade; verbo dar.

Abstract: The work investigates grammaticalization referrals in the modal uses of the verb dar, in contemporary Brazilian Portuguese. The research uses up two corpora of spoken language, the C-ORAL BRAZIL (http:// www.c-oral-brasil.org/) and the minimum corpus of NURC (Norma Urbana Culta). The Functional Discourse Grammar, GDF (HENGEVELD; MACKENZIE, 2008), theoretical and methodological support, includes four grammatical levels (Interpersonal, Representational, Morphosyntatic and Phonological), arranged in descending order. Each of the levels has hierarchically structured layers, which enable the expansion of scopes in modal uses of dar toward the discursive level of the language. The analysis suggests a grammatical change process, stemming from the full forms of the verb, develop quasi-auxiliary forms and hence loose constructions of speech. This development hypothesis is compatible with proposed grammatical paths of formal and semantic change in GDF model (HENGEVELD, in press) and also with other studies on developments in the modal field (BYBEE et al, 1994; TRAUGOTT; DASHER 2002 ), defined as grammaticalization.

Keywords: Functional Discourse grammar; grammaticalization; modality; dar verb.

Data de recebimento: 20 de maio de 2016.

Data de aprovação: 19 de outubro de 2016. 


\section{Considerações iniciais}

Embora a produtividade do verbo dar em diferentes estruturas e valores desperte bastante interesse dos pesquisadores (entre muitos outros: Scher, 2004; Maciel, 2005; Salomão, 2008; Rangel, 2012), seus usos modais, em análise neste trabalho, permanecem como um campo ainda pouco explorado. São usos bastante comuns do verbo, o que em uma pesquisa rápida pela internet facilmente se ressalta. Os enunciados em (1) e em (2), títulos de textos da internet, ${ }^{2}$ exemplificam.

(1) a) Quando dá para descobrir o sexo do bebêe? (http://brasil.babycenter.com/ x4600017/quando-d\%C3\%A1-para-descobrir-o-sexo-do-beb\%C3\%AA)

b) 'Não dá paraentenderporqueleveiumafacadapornada', dizpatinadoraassaltada no Maracanã. (http://oglobo.globo.com/rio/nao-da-para-entender-porque-leveiuma-facada-por-nada-diz-patinadora-assaltada-no-maracana-19197071)

c) Essa panqueca de banana e linhaça (deliciosa!) dá para fazer em minutos. (http://www.valedosolfm.com.br/gastronomia/2016/04/essa-panqueca-de-bananae-linhaca-deliciosa-da-para-fazer-em-minutos/)

(2) d) Eu simplesmente não dou para dona de casa. (https://www.wattpad. com/157666981-vagabond-\%E2\%9C\%BF-chapter-five-\%E2\%9C\%BF-i $\% 27 m$ william)

Os valores de dar, em enunciados como (1) e (2), são modais (PALMER, 1986; AUWERA; PLUNGIAN, 1998; HENGEVELD, 2004; entre outros). Nas ocorrências em (1), dar tem o sentido de ser possivel, em termos de condições favorecedoras para a ocorrência do evento. Em (2), o verbo dar expressa capacidade do sujeito, interpretada em termos de vocação, jeito, aptidão, tendência para algo.

O objetivo deste estudo é, em uma perspectiva sincrônica, investigar padrões de comportamento do verbo dar em usos modais, ressaltando-se deslizamentos funcionais condizentes com a gramaticalização. Utiliza-se, como suporte teórico-metodológico, a Gramática Discursivo-Funcional (HENGEVELD; MACKENZIE, 2008) (doravante, GDF), e se pretende testar a validade dos caminhos previstos pela GDF para processos de gramaticalização.

\footnotetext{
${ }^{2}$ Consulta na internet em 04 de abril de 2016.
} 
A pesquisa serve-se de dois corpora de língua falada, o C-ORAL BRASIL (http://www.c-oral-brasil.org/) e o corpus mínimo do NURC (Norma Urbana Culta).

O C-Oral-Brasil é um corpus de referência da língua portuguesa falada, em contexto natural, organizado por pesquisadores da Faculdade de Letras da Universidade Federal de Minas Gerais (UFMG). As 139 gravações abarcam contexto familiar ou público e cada um desses contextos apresenta três tipos de conversação, em situações bastante diversificadas: monólogos, diálogos e conversações (diálogos com mais de dois participantes).

O chamado corpus mínimo do NURC, também referido como corpus compartilhado do NURC, em que se fundamentou o projeto Gramática do português falado, é constituído por três inquéritos de cada capital abarcada pelo NURC (Porto Alegre, Rio de Janeiro, São Paulo, Recife e Salvador), sendo um de cada tipo - EF, elocução formal, DID, diálogo entre informante e documentador, e D2, diálogo entre dois informantes - , num total de 15 inquéritos. $^{3}$

O texto está estruturado em duas grandes seções, além destas considerações iniciais e das considerações finais que encerram o artigo. Primeiramente, discutem-se aspectos teóricos que sustentam a pesquisa: postulados da GDF relevantes para a análise pretendida, aspectos sobre a gramaticalização e a modalidade na GDF e sobre a gramaticalização de verbos. Em seguida, apresenta-se uma proposta de caracterização funcional de usos modais de dar, em que se revela um percurso de mudança linguística. Nesse exame, avalia-se em que medida os caminhos previstos pela GDF de expansão em direção a camadas e níveis mais altos do modelo se aplicam aos usos modais de dar.

\footnotetext{
${ }^{3} \mathrm{O}$ corpus mínimo do NURC é composto por: D2-SP-360, D2-RJ-355, D2-REC-05, D2-POA-291, D2-SSA-98, DID-SP-234, DID-RJ-328, DID-REC-131, DID-POA-45, DID-SSA-231, EF-SP-405, EF-RJ-379, EF-REC-337, EF-POA-278, EF-SSA-49.
} 


\section{Subsídios teóricos}

\subsection{GDF, aparato teórico-metodológico}

A GDF assume o pressuposto funcionalista segundo o qual as propriedades das expressões linguísticas são adaptáveis aos objetivos comunicativos que o usuário procurar atingir ao usar tais enunciados, e busca descrever os enunciados alinhando a expressão a condicionamentos discursivos.

Considerando-se, então, que um modelo de gramática será mais eficiente quanto mais refletir, em sua organização, o processamento linguístico dos falantes, o que significa a compreensão de que a construção das expressões linguísticas parte da intenção para a codificação, a GDF oferece-se como um modelo teórico da gramática com ordenação hierárquica em níveis, em progressão top-down, do discurso para as unidades menores, como ilustra a figura 1.

FIGURA 1 - Arquitetura geral da GDF

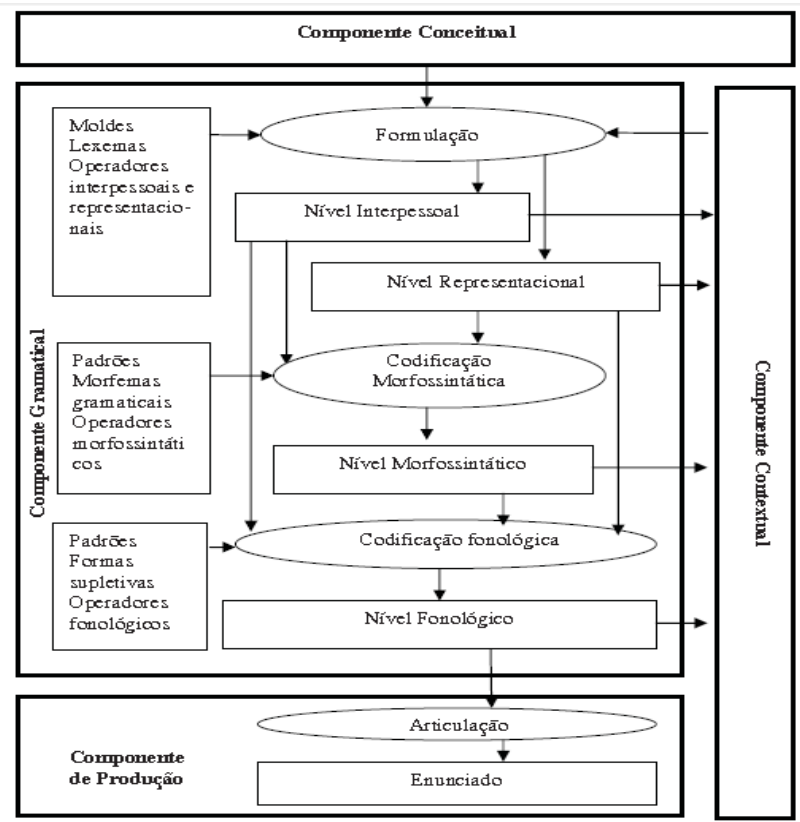

(Fonte: HENGEVELD; MACKENZIE, 2008, p.13) 
Os níveis de representação distinguidos no Componente Gramatical são interligados e organizados de modo descendente: Nível Interpessoal (NI), Nível Representacional (NR), Nível Morfossintático (NM) e Nível Fonológico (NF). Nesse modelo top down, primeiramente se decide o propósito comunicativo para depois se selecionar e se codificar essa informação gramaticalmente. Nessa direção descendente, a pragmática (NI) governa a semântica (NR), a pragmática e a semântica governam a morfossintaxe (NM), e a pragmática, a semântica e a morfossintaxe governam a fonologia (NF).

O Interpessoal e o Representacional são os níveis de formulação, o Morfossintático e o Fonológico, os níveis de codificação. Os quatro Níveis são estruturados em camadas de vários tipos, também hierarquicamente organizadas.

O NI capta todas as distinções de formulação que dizem respeito à interação entre falante e ouvinte. Nele, descrevem-se estratégias para se alcançar objetivos comunicativos. As camadas no NI organizam-se na seguinte ordem hierárquica decrescente quanto ao escopo: Movimento (M) > A to Discursivo (A) > Ilocução (F) > Participantes (P) > Conteúdo Comunicado $(\mathrm{C})>$ Subato de Atribuição $(\mathrm{T})>$ Subato Referencial $(\mathrm{R})$.

O Movimento, camada mais alta do NI, consiste em um ou mais Atos Discursivos, que, por sua vez, organizam-se em um esquema ilocucionário que abarca os participantes da interação e o Conteúdo Comunicado, composto por Subatos, entendidos como formas comunicativas de ação do falante, que podem ser de Atribuição (uma tentativa do Falante de evocar uma Propriedade (f) que se aplica a uma entidade) ou de Referência (uma tentativa do falante de evocar uma entidade, que será de um tipo particular de categoria semântica - por exemplo, Indivíduo (x), Locação (1), Tempo (t), Razão (r). Quantidade (q).

O NR trata dos aspectos semânticos de uma unidade linguística, suas unidades são descritas em termos das categorias semânticas que elas designam. As camadas no NR organizam-se na seguinte ordem hierárquica decrescente quanto ao escopo: Conteúdo Proposicional (p) $>$ Episódio (ep) $>$ Estado-de-coisas (e) $>$ Propriedade Configuracional (f) $>$ Propriedade lexical $>$ Indivíduos (x).

Para este estudo, são de especial relevância as camadas das Propriedades Configuracionais (f), dos Estados-de-coisas (e) e do Conteúdo proposicional (p), pois é nelas que se alocam as modalidades, conforme será explicitado adiante. Conteúdo Proposicional (p), sendo um construto mental, não pode ser localizado no espaço nem no tempo, 
e pode ser avaliado em termos de sua verdade, por exemplo, ideia; Estados-de-coisas (e) podem ser localizados no espaço e no tempo, e podem ser avaliados em termos de sua realidade, por exemplo, encontro; Propriedade (f), que não tem existência independente, não pode ser distinta em termos de tempo e de espaço, e somente pode ser avaliada em termos de sua aplicabilidade a um ou outro tipo de entidade ou a situação que as propriedades em geral descrevem, por exemplo, cor.

O NM é um codificador das informações semânticas e pragmáticas, do input do NI e do NR, é responsável pelas representações estruturais que serão convertidas em construções fonológicas no nível seguinte. Como os demais níveis, o NM é estruturado em camadas ordenadas de modo decrescente: Expressão linguística $(\mathrm{Le})>$ Oração $(\mathrm{Cl})>$ Sintagma $(\mathrm{Xp})>$ Palavra $(\mathrm{Xw})>$ Base $(\mathrm{Xs})>$ Afixo (Aff).

O NF trata, também, de aspectos de codificação. O Componente Fonológico recebe input dos outros Níveis e o traduz em estrutura fonológica. As camadas do NF, em organização hierárquica decrescente, de escopo mais alto para mais baixo são: Enunciado (U) $>$ Frase Entoacional (IP) $>$ Frase Fonológica $(\mathrm{PP})>$ Palavra fonológica $(\mathrm{PW})>$ Pé $(\mathrm{F})>$ Sílaba $(\mathrm{S})$.

Essa breve apresentação da GDF busca oferecer uma visão panorâmica do modelo, com destaque em aspectos mais relevantes para este trabalho. Ao longo do texto, apresentam-se explicitações adicionais do modelo, quando necessárias à compreensão da análise pretendida.

\subsection{Gramaticalização na GDF}

A gramaticalização é compreendida como o processo de mudança linguística pelo qual uma palavra ou expressão lexical torna-se gramatical ou, se já gramatical, torna-se cada vez mais gramatical (HEINE et al., 1991; TRAUGOTT; HEINE, 1991; HOPPER; TRAUGOTT, 2003, entre outros). ${ }^{4}$ Nesse percurso de aumento de gramaticalidade de um item,

\footnotetext{
${ }^{4}$ Estudiosos têm indicado não ser suficiente definir a gramaticalização como processo que envolve um item isolado, sem menção ao ambiente pragmático, semântico em que se dão as mudanças. E vêm ao encontro dessa consideração abordagens construcionais, como bem mostram Nikolas e Patten (2011) e Traugott (2008), entre outros. Embora se admita a pertinência dessa direção de pesquisa, este trabalho não se valerá desta inter-relação. A compatibilidade entre a gramaticalização como concebida na GDF e a mudança linguística como compreendida na abordagem construcional fica por ser melhor avaliada.
} 
alguns conceitos são básicos, a gradualidade (as formas não saltam abruptamente de uma categoria a outra, mas seguem etapas graduais de desenvolvimento) e a unidirecionalidade (as formas seguem a direção de menos para mais gramatical, não o contrário).

A proposta de Heine (2003), já bastante conhecida, busca captar a dinâmica do processo, apresentando quatro mecanismos interrelacionados que entram em ação no processo de gramaticalização: a) extensão (ou generalização contextual) - desenvolvimento de usos em novos contextos; b) dessemantização (bleaching, redução semântica) mudança de conteúdo semântico da forma de origem; c) decategorização (mudança categorial) - perda de propriedades morfossintáticas das formas de origem; d) erosão (ou redução em substância fonética) - decorrente do aumento da frequência de uso do item, a expressão tende a sofrer coalescência (fusão de formas adjacentes) e condensação (diminuição de forma).

Esses parâmetros referem-se a diferentes aspectos da estrutura da língua (pragmática, semântica, morfossintaxe e fonética) e, juntos, caracterizam a gramaticalização.

Existem trabalhos indicando que alterações próprias da gramaticalização podem ser sistematicamente descritas de um modo produtivo utilizando o aparato teórico da GDF (por exemplo: KEIZER, 2007; SOUZA, 2009; HENGEVELD, 2017; OLBERTZ, 2016, CASSEBGALVÃO, 2011, HENGEVELD; HATTNHER, 2016). Com a pretensão de somar-se a esses trabalhos, este estudo busca testar se os caminhos previstos pela GDF para a gramaticalização se aplicam os usos modais de $d a r$.

A hipótese da GDF é que os processos de gramaticalização acarretam gradualmente um aumento sistemático de escopo (HENGEVELD, 2017, p.1), como ilustra a figura seguinte:

FIGURA 2 - Relações de escopo na GDF

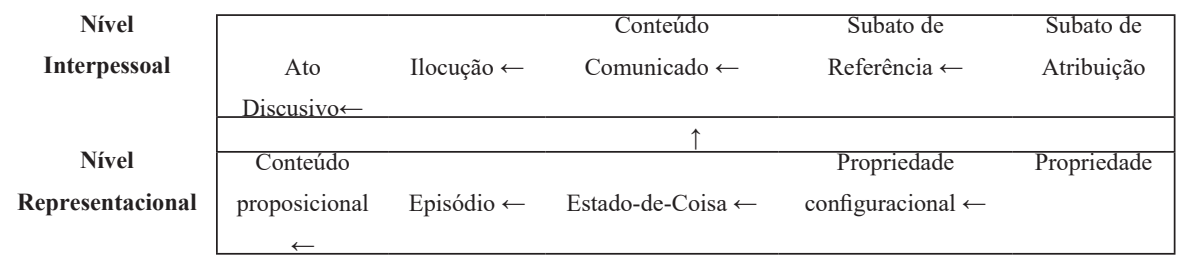

(Fonte: HEGEVELD, 2017, p.3) 
A figura mostra que o modelo prevê três tipos de relações de escopo, com trajetórias nas camadas do NR (p-Conteúdo Proposicional> ep-Episódio $>$ e-Estado de coisa $>$; f-Propriedade Configuracional), nas camadas do NI (M-Movimento> A-Ato Discursivo> F-Ilocução> C-Conteúdo Comunicado $>$ R-Subato de Referência $>$ T- Subato de Atribuição) e, ainda, do NR para o NI.

Tais mudanças de escopo são acompanhadas de mudanças formais que, na gramaticalização, envolvem um decréscimo de lexicalidade. A tarefa de estudar essas mudanças formais passa, então, pela consideração da distinção entre itens lexicais e itens gramaticais. De acordo com a definição de Hopper e Traugott (2003), as palavras lexicais são aquelas usadas para reportar ou descrever coisas, ações, qualidades; as palavras gramaticais, por outro lado, são usadas para indicar relações entre nomes, para ligar partes do discurso, para indicar se entidades e participantes de um discurso já são identificados, e para mostrar se eles estão próximos do falante ou do ouvinte.

$\mathrm{Na}$ GDF, existe uma distinção clara entre elementos gramaticais e elementos lexicais, representados, no modelo, por restritores (ou modificadores) - itens de natureza lexical - e por operadores - itens de natureza gramatical. Modificadores e restritores podem atuar nas diferentes camadas do NR e do NI.

Como estratégias lexicais, os restritores descrevem uma propriedade atribuída a uma entidade, enquanto os operadores, como estratégias gramaticais, especificam as propriedades de uma entidade. Keizer (2007) observa que ambos desempenham uma função restritiva, já que fornecem informações adicionais sobre uma entidade, de forma a ajudar o ouvinte a reconhecer tal entidade. A diferença crucial está na natureza da informação fornecida: os restritores (ou modificadores) restringem a denotação de uma expressão por meio da descrição de uma propriedade da entidade designada (atuam como predicados); os operadores especificam propriedades não descritivas e mais abstratas da entidade.

Uma questão crucial refere-se à fronteira entre elementos gramaticais e lexicais (ou restritores e operadores, na GDF). Nos estudos de gramaticalização, postula-se que a relação entre categorias gramaticais e lexicais não deve ser tomada como rígida, mas gradiente, pautada em um continuum, podendo ser compreendida com base na teoria dos protótipos (TAYLOR, 1995), segundo a qual, ser membro de uma dada categoria 
é uma questão de gradiência. Em outros termos, a categorização não é sempre uma questão de "tudo ou nada", de "lexical ou gramatical", há grupos que combinam características lexicais e gramaticais.

Uma proposta de compreensão dessa gradação, no modelo da GDF, é a desenvolvida por Keizer (2007). A autora aplica a alguns elementos linguísticos (incluindo-se classes, como artigo e numeral; e expressões, como lets e sort-of) critérios usados nos estudos sobre gramaticalização, para definir lexicalidade e gramaticalidade. Nesse exercício, revela-se que os itens associam-se em maior ou menor grau a características próprias de itens gramaticais ou lexicais, o que indica diferentes graus de gramaticalização. A autora distingue quatro grupos mais amplos: itens "primariamente" lexicais, itens "secundariamente" lexicais, itens "secundariamente" gramaticais, itens "primariamente" gramaticais. Essas categorias representam classes com um comportamento gramatical específico, e não classes formais específicas. O quadro seguinte ilustra como esses grupos se associam em um continuum.

QUADRO 1 - Cline revisado de gramaticalização

\begin{tabular}{|c|c|c|c|c|}
\hline \multicolumn{4}{|c|}{$>$ palavras gramaticais } & \multicolumn{2}{c|}{$>$ afixos flexionais } \\
\hline $\begin{array}{c}\text { Elems de conteúdo } \\
\text { primários lexicais }\end{array}$ & $\begin{array}{c}\text { Elementos lexicais } \\
\text { secundários }\end{array}$ & $\begin{array}{c}\text { Elementos gramaticais } \\
\text { secundários }\end{array}$ & $\begin{array}{c}\text { Elementos gramaticais } \\
\text { primários }\end{array}$ & \\
\hline verbo pleno, & expressões & numerais, & artigos, modais, & - s \\
substantivo, & idiomáticas, formas \\
adjetivo & lexicalizadas & pronstrativos, & algumas conjunções e & - ed \\
preposições & - ing \\
\hline \multicolumn{2}{|c|}{ restritores (modificadores) } & ??????? & \multicolumn{2}{c|}{ operadores/ funções } \\
\hline
\end{tabular}

(Fonte: KEIZER, 2007, p. 47)

$\mathrm{Na}$ última linha do quadro, encontram-se os primitivos da GDF. Os elementos lexicais primários e secundários correspondem aos restritores, enquanto os elementos gramaticais primários, aos operadores e funções. Note-se, então, a lacuna: não há primitivo correspondente para os elementos gramaticais secundários.

Para preencher essa posição intermediária, Keizer (2007) propõe um terceiro primitivo, os operadores lexicais. Esses itens não se comportam como operadores prototípicos, e, ao mesmo tempo, diferem bastante, em forma e em função, dos modificadores plenamente lexicais. 
Um novo cline de mudanças formais pode, então, ser definido com as três categorias:

restritores (modificadores) >

(lexicais) operadores lexicais $>$

(posição intermediária entre

lexemas e operadores) operadores

(gramaticais).

Dessa forma, a gradualidade entre lexical e gramatical fica contemplada. Apesar disso, sugere-se, neste trabalho, que, para descrever determinados fenômenos, a gradação deva se ampliar ainda mais, como será mostrado na seção de análise dos dados.

O que importa observar, ainda, é como, na GDF, esses trajetos de mudança formal se inter-relacionam com os de conteúdo.

A hipótese na GDF é a de que um item lexical pode entrar em qualquer ponto do NR ou do NI, e, uma vez que esse ponto tenha sido selecionado, o item não pode se mover para camada ou Nível mais baixo na escala. Mudanças formais e de conteúdo podem ocorrer independentemente, mas sempre seguindo trajeto unidirecional. Quando os elementos se movem para cima ou permanecem onde estão na escala de conteúdo, eles não podem se mover para baixo na escala formal. E, quando os itens se movem para cima ou permanecem onde estão na escala formal, eles não podem se mover para baixo na escala de conteúdo. Isso permite um grande número de combinações de mudanças formais e de conteúdo, algumas delas ilustradas pela figura seguinte, de Hengeveld (2017).

FIGURA 3 - Possibilidades de encaminhamentos formais e de conteúdo na GDF

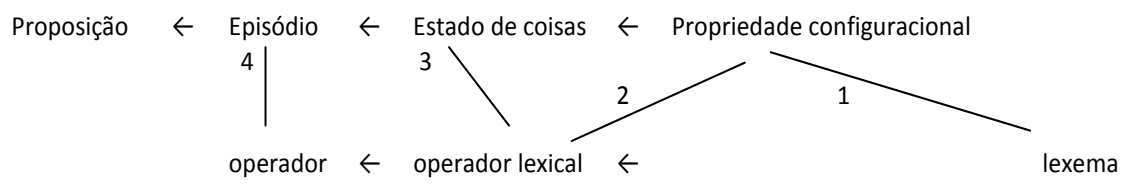

(Fonte: HENGEVELD, 2017, p. 17) 
As quatro setas na figura mostram quatro encaminhamentos possíveis. A situação em (1) representa uma categoria de conteúdo na camada das Propriedades Configuracionais, expressa por meios lexicais. O segundo passo indica que o lexema perde algumas das suas propriedades lexicais e se torna um operador lexical, mas continua expressando o mesmo significado, por isso, ainda se liga à camada das Propriedades Configuracionais. No terceiro passo, o reverso acontece: o elemento em consideração avança na escala de conteúdo, mas mantém as propriedades formais que o caracterizam como um operador lexical. O quarto estágio ilustra uma mudança de conteúdo e de significado, ao mesmo tempo.

\subsection{Gramaticalização de verbos}

Um percurso hipotetizado na gramaticalização de verbos é: verbo pleno $>$ verbo pleno/auxiliar (semi-auxiliar) $>$ verbo auxiliar.

Esse encaminhamento está previsto nos estágios de gramaticalização de verbos distinguidos por Heine (1993), e brevemente resumidos no quadro que segue.

QUADRO 2- Estágios de gramaticalização de verbos, segundo Heine (1993)

\begin{tabular}{|l|c|l|}
\hline \multicolumn{2}{|c|}{ Estágios } & \multicolumn{1}{c|}{ Características gerais } \\
\hline Plenos & A & $\begin{array}{l}\text { O verbo tem significado completamente lexical e se refere a um } \\
\text { objeto concreto. }\end{array}$ \\
\cline { 2 - 3 } & B & $\begin{array}{l}\text { O verbo se associa a verbos não finitos, o complemento se refere a } \\
\text { uma situação, antes que a uma entidade objetiva, o sujeito deve ser } \\
\text { um referente humano. }\end{array}$ \\
\hline Quase auxiliares & C & $\begin{array}{l}\text { O verbo perde restrições em relação ao sujeito (que não se restringe } \\
\text { mais a um referente humano), passa a expressar funções gramaticais } \\
\text { como tempo, aspecto e modalidade. Com a mudança de lexical/ } \\
\text { verbal para uma função mais gramatical o verbo pode tomar como } \\
\text { complemento um verbo com o mesmo étimo como, por exemplo, } \\
\text { have em "Rachel has to have a new flat". }\end{array}$ \\
\hline $\begin{array}{l}\text { Associados } \\
\text { com noção de } \\
\text { auxiliaridade }\end{array}$ & D & $\begin{array}{l}\text { O verbo torna-se defectivo, a caminho de decategorização; associa- } \\
\text { se apenas com formas não finitas. }\end{array}$ \\
\cline { 2 - 4 } & E & $\begin{array}{l}\text { O verbo está completamente decategorizado, tende a ser percebido } \\
\text { pelos gramáticos como pertencente a outra categoria que não a dos } \\
\text { verbos. }\end{array}$ \\
\hline $\begin{array}{l}\text { Auxiliaridade/ } \\
\text { estatuto de afixo }\end{array}$ & F & $\begin{array}{l}\text { O verbo perde completamente as propriedades verbais } \\
\text { remanescentes, firma-se como elemento gramatical. }\end{array}$ \\
\hline $\begin{array}{l}\text { Afixos ou } \\
\text { inflecções }\end{array}$ & G & $\begin{array}{l}\text { O verbo é puramente um marcador gramatical, tipicamente um afixo } \\
\text { monossilábico. }\end{array}$ \\
\hline
\end{tabular}


Para a análise dos usos modais de $d a r$, interessam particularmente os estágios B, C e D de Heine (1993), que envolvem formas verbais a caminho de/em auxiliarização. Nesse processo, é possível identificar algumas tendências de comportamento linguístico, em que o verbo:

a) deixa de se referir a situações concretas, passa a se referir a atividades, eventos e daí a expressar funções gramaticais de tempo, aspecto e modalidade, o que indica aumento de abstratização;

b) passa a se associar a formas verbais não finitas e com elas forma unidade semântica e sintática, constituindo construções monoclausais;

c) torna-se defectivo, não tem formas imperativas, perde a habilidade de ser nominalizado ou apassivizado.

Essas tendências são identificadas também em outros trabalhos que discutem critérios de auxiliaridade, tais como Lobato (1975), Olbertz (1998), Gonçalves (2015).

A gradualidade do processo que leva as formas verbais a se tornarem auxiliares não é desconsiderada. Lobato (1975), por exemplo, distingue entre auxiliantes, auxiliares em sentido amplo, com características intermediárias entre verbos plenos e auxiliares, e auxiliares em sentido estrito, com características prototípicas de verbos em auxiliarização. Olbertz (1998), por sua vez, apresenta testes para que se distinguam verbos lexicais, quase auxiliares e auxiliares, na língua espanhola.

Assim, a gradação verbo lexical >verbo quase auxiliar> verbo auxiliar é considerada em relação à maior ou menor associação a características de verbos em gramaticalização. Pode-se sugerir, então, uma aproximação entre essa gradação e os primitivos da GDF:

$\begin{array}{ccc}\text { restritores }> & \text { operadores lexicais }> & \text { operadores } \\ \text { plenos }> & \text { quase auxiliares }> & \text { auxiliares }\end{array}$

\subsection{Modalidade e gramaticalização}

Hengeveld e Mackenzie (2008) retomam as distinções modais propostas por Hengeveld (2004), dentro do modelo da GDF, descrevendoas no NR. A proposta parte do cruzamento de dois parâmetros, o alvo e o domínio da avaliação modal. 
De acordo com o alvo, ${ }^{5}$ as modalidades são subdivididas em: a) orientada para o participante - localizada na camada das Propriedades Configuracionais (f), afeta a parte relacional da sentença como expressa por um predicado e se refere à relação entre (propriedades de) um participante em um evento e a potencial realização desse evento;

b) orientada para o evento - localizada na camada dos Estados-de-coisas (e), afeta a descrição do evento contido na sentença, ou seja, a parte descritiva de uma sentença e se refere à avaliação objetiva do estatuto de atualidade do evento; em outras palavras, descreve a existência de possibilidades, obrigações gerais, etc, sem que o falante tome responsabilidade por esses julgamentos;

c) orientada para a proposição - localizada na camada do Conteúdo Proposicional (p) afeta o conteúdo proposicional de uma sentença, ou seja, a parte da sentença que representa as visões e as crenças do falante e diz respeito à especificação do grau de comprometimento do falante em relação à proposição que ele está apresentando.

Em relação à variação na perspectiva da avaliação modal (o domínio da avaliação), Hengeveld (2004) propõe os seguintes tipos de modalidade: facultativa (referente à capacidade intrínseca ou adquirida); deôntica (referente àquilo que é permissível - legalmente, socialmente, moralmente); volitiva (referente àquilo que é desejável); epistêmica (referente àquilo que se conhece sobre o mundo atual); evidencial (referente à origem da informação contida sobre o mundo atual).

O quadro 3 apresenta as combinações possíveis entre os domínios e os alvos modais.

\footnotetext{
${ }^{5}$ Hengeveld (2011) propõe uma modificação nessa classificação, distinguindo um quarto alvo de avaliação modal, a modalidade orientada para o episódio que, em Hengeveld (2004), foi considerada como um subtipo de modalidade, a orientada para o evento epistêmica (objetiva). De acordo com Hengeveld (2011), a modalidade epistêmica objetiva caracteriza episódios em termos da (im)possibilidade de sua ocorrência em vista daquilo que é conhecido sobre o mundo. A distinção entre a modalidade orientada para o evento e a orientada para o episódio se relaciona com tempo. Na orientada para o episódio, o tempo é absoluto, independente, e, na orientada para o evento, o tempo é relativo, dependente. Para este estudo, essa distinção não é relevante e, por isso, não se considera essa modificação da classificação de Hengeveld.
} 
QUADRO 3 - Classificação das modalidades segundo Hengeveld (2004)

\begin{tabular}{|c|c|c|c|}
\hline Domínio Alvo & Participante & Evento & Proposição \\
\hline facultativa & + & + & - \\
\hline deôntica & + & + & - \\
\hline volitiva & + & + & - \\
\hline epistêmica & - & + & + \\
\hline evidencial & - & - & + \\
\hline
\end{tabular}

Considerando-se a relação hierárquica das camadas nas quais se alocam, as modalidades orientadas para o participante, para os estados de coisas e para a proposição apresentam diferentes relações de escopo, que são adequados para a descrição de diferentes graus de gramaticalidade de elementos modais. Torna-se possível, assim, hipotetizar trajetos de desenvolvimento gramatical no campo modal, como ilustra a figura seguinte:

FIGURA 4 - Hipótese de gramaticalização na GDF para campo modal

\begin{tabular}{|c|c|c|}
\hline \multicolumn{3}{|c|}{ Nível Representacional } \\
\hline (f) & (e) & (p) \\
\hline $\begin{array}{l}\text { Propriedades Configuracionais } \\
\text { (modalidade orientada para o falante) }\end{array}$ & $\begin{array}{c}\text { Estados-de-coisas } \\
\text { (modalidade orientada para } \\
\text { o evento) }\end{array}$ & $\begin{array}{c}\text { Conteúdo Proposicional } \\
\text { (modalidade orientada para } \\
\text { a proposição) }\end{array}$ \\
\hline
\end{tabular}

Essas hipóteses de percurso são compatíveis, como já apontado por Hengeveld; Hattnher (2016), com previsões de encaminhamentos de gramaticalização no campo modal formulados por outros pesquisadores, pautados em outros modelos teóricos como, por exemplo, Traugott e Dasher (2002) e Bybee et al. (1994).

$\mathrm{O}$ que esses estudos apontam é que o desenvolvimento no campo modal se dá do mais concreto ao mais abstrato, com aumento gradual de subjetividade. Traugott e Dasher (2002, p. 147) postulam que o desenvolvimento se dá na direção de significados deônticos para epistêmicos, com aumento de escopo e de grau de subjetividade. Bybee et al. (1994) defendem o seguinte trajeto de desenvolvimento em direção ao valor possibilidade epistêmica:

habilidade $>\quad$ possibilidade de raiz/ permissão $\quad>\quad$ possibilidade epistêmica 
O percurso de mudança prevê que, de um significado mais concreto (habilidade) surgem significados mais abstratos, mais subjetivos, mais centrados nas crenças e opiniões do falante (valores epistêmicos), desenvolvendo-se, antes, possibilidade de raiz e permissão.

\section{Caracterização funcional de usos modais de dar}

Localizaram-se 131 ocorrências de usos modais de dar, sendo 105 do C-Oral-Brasil e 26 do NURC. Os valores modais assumidos por dar, nos textos examinados, são, conforme classificação de Hengeveld (2004), facultativo orientado para o participante, como em (3), facultativo orientado para o evento, como em (4), e deôntico orientado para o evento, como em (5).

\section{(3) Facultativo orientado para o participante}

*JRM: [266] fiquei lá um tempo / depois vim pa área de cá //\$

*JRM: [267] trabalhei até aqui / o' / nesse salão aqui do lado //\$

*JAN: [268] uhn //\$

*JRM: [269] hum hum //\$

*JRM: [270] comecei fazer curso dali / curso daqui / tal / tal tal //\$

*JRM: [271] adoro //\$

*JRM: [272] gosto de mexer com química e cortar //\$

*JRM: [273] penteado / é Maria //\$

*JRM: [274] eu nũ dou pra penteado de jeito nenhum //\$

*JRM: [275] adoro //\$

*JRM: [276] gosto mesmo //\$

*JRM: [277] e aqui tá melhor ainda / porque a gente trabalha do jeito que gosta / $\$$ (C-Oral, bfamd122)

(...) eu não dou para penteado de jeito nenhum $(\ldots)^{6}$

\footnotetext{
${ }^{6} \mathrm{O}$ corpus C-ORAL BRASIL utiliza critérios aprimorados para transcrição que buscam captar marcas prosódicas, segmentação dos dados falados. O desconhecimento das convenções de transcrição gera dificuldade para a leitura dos exemplos. Optou-se, então, por manter a apresentação dos exemplos, tal como está no corpus, e oferecer, na sequência, o enunciado em análise com marcas convencionais de escrita (vírgula, ponto final).
} 


\section{(4) Facultativo orientado para o evento}

*REG: [7] custei a vestir / só tirei a blusa do meu pijama / fui com o short mesmo e vesti um vestido por cima / e dali eu andei do quarto [/2] do meu quarto até na copa já tinha que assentar // \$

*REG: [8] da copa até na sala tinha que assentar //\$

*REG: [9] porque a contração já vinha assim / de três em três passos já nũ dava pa andar //\$

*REG: [10] aí deitei no carro lá atrás //\$

(C-Oral, bfmmn.28)

(...) porque a contração já vinha assim de três em três passos, já não dava para andar (...)

\section{(5) Deôntico orientado para o evento}

*BRU: [85] o filhote tá começando a ficar com fome / tal / e aí eles fazem a coisa //\$

*BRU: [86] que nũ pode contar / nũ dá //\$

*PRI: [87]<tá hhh>//\$

*JAN: [88] <que coisa $>/ / \$$

*BRU: [89] <tem que assistir $>/ / \$$

*PRI: [90] <não / é> do filme //\$

*JAN: [91] <mas que coisa $>/ / \$$

*PRI: [92] nũ quero saber //\$

*BRU: [93] nũ dá pra contar o final do filme //\$

*JAN: [94] eu vou olhar na internet //\$

*PRI: [95] ah / <por que que cê nũ assiste > / hein //\$

(C-ORAL, bfmacv22)

(...) não pode contar, não dá (...)

(...) não dá para contar o final do filme (...)

A grande maioria das ocorrências examinadas, 89\%, expressa o valor facultativo orientado para o evento, como em (4). Vem ao encontro desse resultado a pesquisa de Velloso (2007) sobre usos modais de dar, em que se notou que a grande maioria dos enunciados se concentra em valores habilitativos (de raiz), que, na classificação adotada neste trabalho, seriam usos facultativos orientados para o evento.

Neste estudo, apenas 5\% são do tipo deôntico orientado para o evento, como (5), e 1\% é facultativo orientado para o participante, como 
(3). Há, ainda, 5\% das ocorrências ambíguas entre os valores facultativo e deôntico orientados para o evento.

Outro resultado relevante surge com a observação dos contextos negativos e das formas flexionais do verbo, em que se revela predominância de formas negativas $(53 \%)$, no presente do indicativo $(80 \%)$ e na terceira pessoa do singular $(98 \%)$, o que aponta para uma rotinização da forma não dá, como nas ocorrências apresentadas em (5).

Nas próximas subseções, analisam-se cada um dos valores modais identificados para dar no corpus da pesquisa, estudam-se propriedades funcionais desses usos, salientando-se encaminhamentos próprios de gramaticalização.

\subsection{Facultativo orientado para o participante}

A modalidade facultativa orientada para o participante, localizada na camada das Propriedades Configuracionais (f), no NR da GDF, afeta a parte relacional da sentença como expressa por um predicado e se refere à relação entre (propriedades de) um participante em um evento e a potencial realização desse evento. No domínio facultativo (referente à capacidade intrínseca ou adquirida), descreve-se a habilidade de um participante de se envolver no tipo de evento designado pelo predicado.

Nesse caso, o verbo dar expressa capacidade do sujeito, interpretada em termos de vocação, jeito, aptidão, tendência para algo. No enunciado (3), (...) eu não dou para penteado de jeito nenhum (...), a informante, uma cabeleireira, diz que não tem habilidade, vocação para fazer penteados. Embora esse sentido para o verbo dar seja familiar aos usuários da língua, essa ocorrência foi a única do tipo localizada nos textos selecionados para exame. Considere-se, ainda, que se trata de uma sentença negativa, mas que esse valor modal se realiza com o verbo dar também na forma afirmativa, como é possível verificar em outros corpora. Salomão (2008, p.84), por exemplo, apresenta o seguinte enunciado: Carlos dá para linguista.

Nesses usos, dar é verbo pleno, seleciona argumentos, um NP (noun phrase, sintagma nominal) na função sujeito, e um NP na função complemento, antecedido pela preposição para, ocorre no padrão estrutural $N p+D A R+P A R A N p$. O verbo atua, então, como um restritor/ modificador da camada (f), no modelo da GDF. Na escala dos valores modais, é o uso mais concreto, baseado em descrições de situações externas. 


\subsection{Facultativo orientado para o evento}

A modalidade orientada para o evento afeta a descrição do evento contido na sentença, ou seja, a parte descritiva de uma sentença, e se refere à avaliação objetiva do estatuto de atualidade do evento. Em outras palavras, descreve a existência de possibilidades, obrigações gerais, etc, sem que o falante tome responsabilidade por esses julgamentos (HENGEVELD; MACKENZIE, 2008, p.174).

Esse valor modal caracteriza-se em termos de condições circunstanciais ou físicas que permitem a ocorrência do evento descrito na sentença. Diferentemente das ocorrências facultativas orientadas para o participante, não se refere à capacidade intrínseca ou adquirida de um participante, a possibilidade de ocorrência de um evento não depende das aptidões de um participante, mas se liga às circunstâncias de um evento.

A ocorrência (4), (...) porque a contração já vinha assim de três em três passos, já não dava para andar (...), já apresentada, é exemplo. A informante relata o momento em que estava em trabalho de parto e que, devido às contrações, não dava para andar, ou seja, não havia condições de andar. O verbo dar, nesses casos, é parafraseável por ser possível, em termos de condições favorecedoras para a ocorrência do evento.

Note-se que a possibilidade é expressa sem que o falante tome responsabilidade por esse julgamento. Ou seja, a expressão não é apresentada como uma opinião pessoal. Isso fica registrado com a forma impessoal, cujo efeito de sentido é de maior descomprometimento, distanciamento do enunciador com o que está sendo apresentado.

É preciso observar, ainda, que esses usos modais podem estar a serviço de estratégias pragmáticas, em que a modalização com dar é um recurso de gerenciamento da interação verbal:

(6) *EDE: [256] ô gente / nũ dá p' cês falar mais alto / que não tá pegando //\$

*MAR: [257] é mesmo //\$

*EDE: [258] é / <cê tem que> gritar mesmo // \$

*JUL: [259] <é> //\$

(C-Oral, bfmacv15)

Ô gente, não dá pra vocês falar mais alto que não tá pegando?

A pergunta, em (6), é realizada pela pessoa responsável pela gravação e visa a solicitar que os informantes falem mais alto para 
que haja maior qualidade da gravação. Essa demanda pode ser vista como constrangedora para os informantes e EDE parece se antecipar a isso, modalizando seu enunciado, além de colocar o pedido em forma de um questionamento, não em forma de um imperativo. Nesse sentido, compreende-se que dar, em (6), envolve intersubjetividade (TRAUGOTT, 2010), pois reflete preocupação do interlocutor com a recepção de seu enunciado. Em outros termos, o conteúdo do ato de fala do enunciador é sentido por ele como, de algum modo, ameaçador da face do interlocutor, então a modalização é usada como um recurso pragmático para diminuir a força desse ato de fala. ${ }^{7}$

O padrão formal dos usos facultativos orientados para o evento é importante dado para análise de seu desenvolvimento gramatical. Nesses enunciados, o verbo assume a forma impessoal e é seguido por complemento não finito introduzido pela preposição para (como em não dava para andar; não dá para falar mais alto?): DAR (forma impessoal) + PARA V $p^{8}$ (forma não finita). Diferentemente dos usos facultativos orientados para o participante (eu não dou para penteado), nos facultativos orientados para o evento, dar não têm função de predicado principal por si mesmo, ou seja, há ausência de propriedade de predicação (detematização). A predicação é constituída pelo verbo em associação à forma verbal infinitiva introduzida pela preposição para. Evidencia-se, assim, um encaminhamento em direção à auxiliarização.

Há de se notar, também, aumento de abstratização, em que o verbo deixa de se referir a um estado físico de um indivíduo (a uma vocação, nos usos facultativos orientados para o participante), e passa a se referir a uma atividade, a um evento, avaliado em termos da possibilidade de sua realização.

O verbo dar atua, nessas ocorrências, como um quase auxiliar (HEINE, 1993), um verbo que assume uma função mais gramatical que os verbos plenos, com traços característicos de auxiliaridade. A partir dessas análises, propõe-se, neste estudo, que esses usos sejam entendidos como operadores lexicais, na GDF.

\footnotetext{
${ }^{7}$ Para mais informações sobre a modalidade como um recurso de gerenciamento da interação verbal, sugerem-se Hoffnagel (1997), Miranda (2000), Carrascossi (2013), entre outros.

${ }^{8}$ Vp é Verbal phrase, sintagma verbal.
} 
Observe-se, ainda, a possibilidade de o verbo ocorrer independentemente, quando o contexto permite. Olbertz (1998) indica que expressar as funções gramaticais sem a presença de uma combinação com um componente lexical verbal, quando uma situação conceitual a ser modificada foi especificada imediatamente antes, é uma propriedade típica de quase auxiliares. É o que se nota nas ocorrências seguintes:

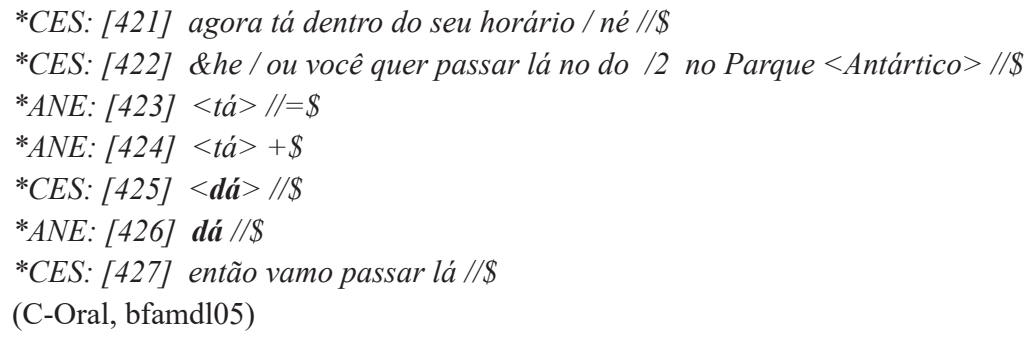

CES: Agora tá dentro do seu horário, né? Ou você quer passar lá no Parque Antártico? ANE: Tá, tá

CES: Dá?

ANE: Dá.

Nesses casos, a forma impessoal dá é uma peça avulsa, fixa, rotinizada, com escopo sobre porções do discurso. Em (7), dá modaliza um Ato Discursivo do outro interlocutor (você quer passar lá no Parque Antártico). As duas ocorrências, em (7), podem ser parafraseadas por Dá para passar no Parque Antártico (?). Dessa forma, o funcionamento da construção está em dependência do fluxo conversacional. A forma modal dá, nesses casos, estabelece dependência apenas discursiva (e não morfossintática, como em não dava para andar, por exemplo) com o conteúdo modalizado.

Em relação ao nível de atuação, há, então, um aumento de escopo, em que o verbo passa atuar no NI. Esses usos apresentam-se, assim, com grau maior de gramaticalidade que aqueles que atuam no NR. A proposta deste trabalho é que sejam compreendidos também como operadores

\footnotetext{
${ }^{9}$ A GDF assume a definição de Kroon para Atos Discursivos: 'the smallest identifiable units of communicative behavior. In contrast to the higher-order units called Moves they do not necessarily further the communiation in terms of approaching a conversational goal' (KROON, 1995, p.65 apud HENGEVELD; MACKENZIE, 2008, p.60).
} 
lexicais na GDF, mas, para distingui-los dos operadores lexicais no NR, utilizam-se os termos operadores lexicais $1(N R)$ (como (6)) e operadores lexicais 2 (NI) (como 7)).

Interessantemente, como uma fórmula rotinizada, com funcionamento fortemente ligado ao fluxo conversacional, dá pode apresentar escopo difuso, captável na situação comunicativa compartilhada entre os interlocutores. É o caso das ocorrências (8) e (9), em que a modalização com dar recai sobre uma situação compartilhada entre os participantes da comunicação, um conteúdo linguisticamente não detectável.

(8) *MUR: [283] vira / vira pra cá //\$

*MUR: [284] celera //\$

*MUR: [285] fecha / celera //\$

*MUR: [286] celera //\$

*MUR: [287] fecha agora //\$

*MUR: [288] tudo //\$

*MUR: [289] xá eu ver //\$

*MUR: [290] xá eu ver //\$

*MUR: [291] ah / tá //\$

*MUR: [292] dá / <nũ dá não> //\$

*ELI: [293] < nũ dá não> //\$

*MUR: [294] cê tem que voltar //\$

*MUR: [295] pergunta o seu namorado se dá //\$

*ELI: [296] dá //\$

*ELI: [297] nũ dá não / né //\$

(C-Oral,bpubd104)

(9) L2 - (...) eu saí de casa... estava sem dinheiro... fui pra escola passei o tempo todo... disse... bom... eu antes de ir pro aeroporto entrava ... ia pra Curitiba às quatro horas da tarde e antes de ir pro aeroporto eu disse... bom... eu passo na agência do Banco do Brasil na Ilha... na Ilha... ah do Fundão... na universidade ... então cheguei lá... fila quilométrica ... disse bom ... aqui não dá ... então eu vou pro aeroporto ... cheguei no aeroporto ... uma agência tranquila ... fui lá ... tirei os mil e quinhentos cruzeiros... fui viajar.. quer dizer ... uma tranquilidade...

(D2 RJ 355)

Em (8), os vários usos da forma (não)dá são enunciados em uma situação na qual alguém ensina outra pessoa a dirigir e se avaliam, em termos de possibilidade de serem bem sucedidas, as manobras do 
motorista aprendiz. Em (9), não dá refere-se à impossibilidade, para o enunciador, de esperar para ser atendido em uma agência bancária, à ausência de condições favoráveis à sua permanência naquele local.

Note-se que a modalidade, em enunciados como esses, tem âmbito de incidência difuso, captável no fluxo interacional, implicado na situação comunicativa. Ou seja, dá não estabelece relação modal canônica, no nível interno das sentenças, mas atua no nível dos atos de fala, das relações interpessoais, tem atuação no NI.

Outro uso cujo padrão estrutural é motivado pragmaticamente é exemplificado em (10), também com o valor facultativo orientado para o evento. Nesses casos, um Np é localizado em posição inicial e pode ser analisado como sujeito morfossintático da construção. $\mathrm{O}$ padrão estrutural, nessas ocorrências, é $N p+D A R+P A R A V p$.

(10) (a) L1-porque viajar de kombi nao é moleza viu?

L2 - nao eu tô acost/ nao prá mim tá bom porque é na minha média...eu não viajo nem num outro carro acima de oitenta ou noventa...de velocidade... $\underline{\text { a }}$ Kombi dá prá fazer isso de modo que eu vou tranquilo...eu pretendo chegar sair daqui...sexta-feira de manha prá poder estar no sábado em Belo Horizonte...tranquilo (D2 SSA 98)

\section{A Kombi dá pra fazer isso.}

(b) Dá pra fazer isso com a Kombi

Assume-se que o enunciado $A$ Kombi dá pra fazer isso expressa a modalidade facultativa orientada para o evento, pois existem condições circunstanciais (no caso, a potência do motor da Kombi) que habilitam a ocorrência do evento (viajar até a velocidade de 80 ou 90 quilômetros por hora). Entende-se que $a$ Kombi, em (10a), é sujeito morfossintático da construção, mas, em termos semânticos, é adjunto adverbial, como mostra a paráfrase (10b).

A motivação para esse posicionamento do sintagma está no conflito entre estatuto dado, ativo, de um referente e sua localização em um domínio que não contribui para a coesão discursiva e continuidade referencial. Note-se, no trecho selecionado em (10a), que a conversação entre os informantes do NURC é sobre automóveis utilizados em viagens. L1 diz que viajar de Kombi não é moleza, ou seja, não é algo muito bom, referindo-se à falta de potência do motor desse veículo. L2 
responde argumentando contrariamente, dizendo que não vê problemas em viajar com Kombi. Assim, nesse momento da conversa, o elemento discursivamente relevante é a Kombi, por isso ele é resgatado por L2 em posição de destaque, no início da oração, assumindo a função pragmática Tópico.

Na GDF, a função Tópico é atribuída a um Subato Referencial, do NI, que tem função de sinalizar, no Ato Discursivo, como o Conteúdo Comunicado se relaciona ao registro construído gradualmente no Componente Contextual; representa uma entidade sobre a qual se faz uma predicação. ${ }^{10}$

Ocorrências como (10a) são casos de topicalização (PONTES, 1987), aparentados com fenômenos de alçamento (NOONAN, 2007), em que há uma alteração na estrutura sintática determinada por fatores pragmáticos. Um Np é localizado no início do enunciado, uma posição de destaque na interação, porque é um elemento relevante, saliente no discurso. Esses usos, no corpus da pesquisa, sempre têm o valor facultativo orientado para o evento.

A posição inicial dos enunciados tem sido tradicionalmente associada à função sintática de sujeito. Garcia Velasco (2013) nota que não é novidade para os estudiosos que a posição de sujeito tem sido relacionada com a codificação de informação dada e, por isso, é natural que, quando se deseje destacar algum item, a posição desse item seja a de sujeito, afinal, a codificação de um elemento como sujeito é uma estratégia para sinalizar seu estatuto ativo, dado, na interação verbal.

Diz Pezatti (2015) que a atribuição da função Tópico, em português, é marcada pela colocação do Subato Tópico no início da construção, o que significa que está sempre em posições do domínio de $\mathrm{P}^{\mathrm{I}}$ (posição inicial) na codificação morfossintática e "o candidato mais natural à função Tópico é, sem dúvida, o constituinte configuracional que morfossintaticamente desempenha a função de Sujeito" (PEZATTI, 2015, p.8).

\footnotetext{
${ }^{10}$ Além da função Tópico, a GDF distingue mais duas funções pragmáticas que podem ser atribuídas aos Subatos: Foco e Contrate. A função Foco marca a seleção estratégica do falante de informação nova para preencher uma lacuna na informação do seu interlocutor. O Contraste sinaliza o constituinte que carrega a informação mais saliente; assinala o desejo do falante de realçar diferentes particularidades entre dois ou mais Conteúdos Comunicados ou entre Conteúdo Comunicado e informação contextualmente disponível.
} 
Verificam-se, nesses casos de topicalização, ajustes morfossintáticos. Na ocorrência (10a), há a perda da preposição com do adjunto adverbial, em (10b). Pode-se verificar, ainda, concordância do verbo com o sujeito, mais evidente em casos nos quais o sujeito é plural, como (11).

(11a) *ROG: [181] aqui ainda tá bom $/ / \$$

*ROG: [182] ea tem que ser mais seca mesmo //\$

*PAU: [183] aqueas pedras mais finas dão pa calçar aqui //\$

*ROG: [184] sior fala aqueas que tá ali //\$

*ROG: [185] aquelas que \&t [/1] no passeio lá embaixo //\$

*PAU: [186] é //\$

*ROG: [187] dá //\$

*ROG: [188] tem muita pedra ali / uai //\$

(C-Oral, bpubd101)

Aquelas pedras mais finas dão para calçar aqui.

(11b) Dá para calçar aqui com aquelas pedras mais finas.

Em (11a), aquelas pedras mais finas é um constituinte relevante na interação, o tópico do enunciado, e, por isso, assume a posição inicial. O elemento adverbial em (11b), com aquelas pedras mais finas, em (11a), está em posição inicial e em função sujeito e, nessa posição, há ajuste morfossintático: perda da preposição $(\mathrm{com})$ e concordância do verbo (dão) com o sujeito (aquelas pedras mais finas).

A proposta, portanto, é a consideração de (10b) e (11b) (dá para fazer isso com a Kombi; dá para calçar aqui com aquelas pedras mais finas) como paráfrases de (10a) e (11a) (a kombi dá para fazer isso; aquelas pedras mais finas dão para calçar aqui). Entretanto, se não se consideram esses enunciados como variantes, analisam-se as ocorrências (10a) e (11a) como expressão da modalidade facultativa orientada para o participante (f), em que um participante (nos casos exemplificados, $a$ kombi e aquelas pedras mais finas) estão sendo qualificados. 


\subsection{Deôntico orientado para o evento}

O último valor modal de dar a ser discutido é o deôntico orientado para o evento, que caracteriza estados de coisas em termos daquilo que é obrigatório ou permitido em um sistema de convenções morais ou legais, regras de conduta (HENGEVELD; MACKENZIE, 2008, p. 174).

Usos deônticos orientados para o evento representam regras de conduta, de modo geral, não referentes a um participante em particular. No trecho já apresentado em (5), uma conversa entre amigas na qual uma conta o enredo de um filme, há duas ocorrências, (...) não pode contar, não dá (...) e (...) não dá para contar o final do filme.

A fonte deôntica, em (5), é pautada em regras de convívio social, segundo as quais não se pode contar toda a história de filmes, livros, o que retiraria parte do prazer daquele que ainda terá contato com a obra. E, com base nessa fonte deôntica, se compreende a ausência de permissão em não dá para contar o filme e não dá .

Os casos de usos deônticos com dar não são muito frequentes, correspondem a 5\% das ocorrências localizadas, e são sempre orientadas para o evento.

O padrão estrutural dos usos deônticos de dar não diferem dos facultativos orientados para o evento, ocorrem em estrutura impessoal, seguido de uma forma não finita introduzida pela proposição para: $D A R$ (forma impessoal) + PARA Vp (forma não finita). O verbo atua como um quase auxiliar e na GDF corresponde a operadores lexicais na camada (e), que se designam, neste trabalho, como operadores lexicais 1 para distingui-los daqueles que atuam no NI (operadores lexicais 2), conforme discutido.

\subsection{Generalizações sincrônicas}

As análises revelam uma expansão dos escopos nos usos modais de dar em direção a camadas e níveis mais altos do modelo da GDF, interpretada como indício de processo de gramaticalização. Os usos modais de dar examinados alocam-se nas camadas das Propriedades Configuracionais (f) e dos Estados-de-coisas (e), do NR, e daí para o NI, podendo se alocar na camada dos Atos Discursivos (A), revelando a trajetória $(\mathrm{f})>(\mathrm{e})>\mathrm{NI}$, conforme a destaca figura: 
FIGURA 5 -Trajetória de desenvolvimento gramatical e discursivo em usos modais de dar ${ }^{11}$

\begin{tabular}{|c|}
\hline Nível Interpessoal $\left(\mathrm{M} \leftarrow\left(\mathrm{A}_{\uparrow} \leftarrow(\mathrm{F} \leftarrow(\mathrm{C} \leftarrow(\mathrm{R} \leftarrow(\mathrm{T}))))\right)\right)$ \\
\hline Nível Representacional $(\mathrm{p} \leftarrow(\mathrm{ep} \leftarrow(\mathbf{e} \leftarrow)(\mathbf{f}$ \\
\hline
\end{tabular}

Nesse trajeto de mudanças de conteúdo, o verbo apresenta também alterações formais, em direção a um decréscimo de lexicalidade: restritor/modificador $>$ operador lexical $1(N R)>$ operador lexical 2 (NI).

$\mathrm{Na}$ camada das propriedades configuracionais (f), NR, dar realiza-se como um verbo pleno, um restritor/ modificador, expressão de habilidade de um sujeito participante em termos de vocação, tendência, configurando a modalidade facultativa para o participante (Eu não dou para penteado).

Na camada dos Estados-de-coisas (e), NR, dar atua como um operador lexical, um quase auxiliar introduzindo um verbo infinitivo por meio da preposição para. A interpretação modal, nesse caso, é facultativa orientada para o evento, em que se descreve a possibilidade de ocorrência de um evento em termos das condições circunstanciais que habilitam sua realização (a contração vinha de três em três passos, já não dava para andar), ou deôntica orientada para o evento, em que se descreve um estado-de-coisas como permitido, com base em um sistema de convenções morais ou legais, regras de conduta (não dá para contar o final do filme).

Como uma fórmula fixa e avulsa, dá tem seu funcionamento ligado ao fluxo interacional, configurando-se como um elemento no NI, com atuação na camada do Ato Discursivo, mas que pode ter âmbito de incidência difuso, implicado na situação comunicativa. Considerando-se que esse uso avança na gradação de gramaticalidade como proposta na GDF, utiliza-se o termo operador lexical 2 para distingui-lo do uso na camada dos Estados-de-coisas, no NR (operador lexical 1).

É possível, então, inferir um processo de mudança, em que há um deslizamento da gramática ao discurso, com aumento de abstratização

\footnotetext{
${ }^{11}$ As camadas do NI representadas são: M - Movimento; A - Ato Discursivo; C-Conteúdo Comunicado; F-Subato de Referência; T-Subato de Atribuição. As camadas do NR representadas esquema são: p-Conteúdo Proposicional; ep- Episódio; e- Estado-decoisas; f- Propriedade Configuracional.
} 
e perda propriedades lexicais, compatíveis com a gramaticalização. A figura 6 ilustra esses encaminhamentos.

FIGURA 6 - Trajetos de desenvolvimento de usos modais de dar

\begin{tabular}{|cccccc|}
\hline verbo pleno & $\rightarrow$ & \multicolumn{3}{c|}{ verbo quase auxiliar } \\
restritor & $\rightarrow$ & operador lexical 1 & $\rightarrow$ & operador lexical 2 \\
Propriedades Configuracionais (NR) & $\rightarrow$ & Estados-de-Coisas (NR) & $\rightarrow$ & NI \\
\hline
\end{tabular}

O esquema destaca as extensões verificadas na análise dos usos modais de dar, a partir das quais é possível inferir um processo de mudança, que parte de formas plenas, se desenvolvem formas quase auxiliares do verbo e daí fórmulas fixas do discurso. Tal hipótese de desenvolvimento é compatível com propostas de percursos gramaticais de mudança semântica e formal no modelo da GDF (HENGEVELD, 2017) e, ainda com outros estudos sobre o desenvolvimento no campo modal (BYBEE et al., 1994; TRAUGOTT; DASHER, 2002).

\section{Considerações finais}

Com base no modelo teórico da GDF, foram estudadas ocorrências de língua falada do português contemporâneo de usos modais do verbo dar, em seus aspectos pragmáticos, semânticos e morfossintáticos.

As analises mostram a GDF como aparato teórico-metodológico consistente com o estudo da fluidez de usos modais com dar, na língua portuguesa.

Foi possível descrever os usos novos e cristalizados de dar em uma sequência na expansão dos escopos no NR, e daí para o NI da GDF. As mudanças de conteúdo se inter-relacionam com alterações formais. Em termos formais, utilizando-se os primitivos da GDF, pôde-se verificar a escala restritor/modificador $>$ operador lexical $1(N R)>$ operador lexical 2 (NI).

Observou-se que fatores discursivos e semânticos interferem na estruturação morfossintática dos usos modais de dar. À medida que os usos se tornam mais ligados ao funcionamento do nível discursivo, a estrutura se torna cada vez mais avulsa, mais livre em termos morfossintáticos. 
Dessa forma, o exame revela um deslizamento no funcionamento da construção, da gramática ao discurso, com aumento de abstratização e perda de propriedades lexicais, compatível com processos de gramaticalização (HENGEVELD, 2017).

Note-se, por fim, que esse percurso do verbo dar no campo modal é baseado em generalizações sincrônicas. Como defendem Hopper e Traugott (2003), um cline sincrônico representa um rearranjo das formas, é uma hipótese. A busca por comprovação em outras sincronias para o percurso de desenvolvimento gramatical que as análises no português contemporâneo permitem está em processo, e seus resultados serão discutidos em outro trabalho.

\section{Referências}

AUWERA, J. V.; PLUNGIAN, V. Modality's semantic map. Linguistic Typology, Mouton de Gruyter, v. 2, p. 79-124, 1998.

BYBEE, J. L.; PERKINS, R. D.; PAGLIUCA, W. The evolution of grammar. Tense, aspect and modality in the language of the world. Chicago: University of Chicago Press, 1994.

CARRASCOSSI, C.N.S. O papel da modalização no jogo discursivo: um estudo da construção pode ser (...), mas ... Estudos Linguísticos, São Paulo, v. 42, n. 1, p. 87-99, jan.-abr. 2013.

CASSEB-GALVÃO, V.C. Gramática discursivo-funcional e teoria da gramaticalização: revisitando os usos de [diski] no português brasileiro. Filologia e Linguística Portuguesa, São Paulo, v. 13, n. 2, p. 305-335, 2011. https://doi.org/10.11606/issn.2176-9419.v13i2p305-335

GARCIA VELASCO, D. G. Raising in functional discourse grammar. In: MACKENZIE, J. L.; OLBERTZ, H. (Ed.) Casebook in Functional Discourse Grammar. Amsterdam: Benjamins, 2013. p. 249-279. https://doi.org/10.1075/slcs.137.10vel

GONÇALVES, S. C. L. Auxiliaridade em construções perifrásticas da cadeia TAM e frequência de uso: dois critérios e um problema. In: OLIVEIRA, Mariangela Rios; ROSÁRIO, Ivo. (Org.). Linguística centrada no uso. Rio de Janeiro: Lamparina/Faperj, 2015. v. 1, p. 113-128. 
HEINE, B. Auxiliares - Cognitive forces and grammaticalization. New York; Oxford: Oxford University Press, 1993.

HEINE, B. Grammaticalization. In: JANDA, R. D.; JOSEPH, B. D. (Ed.). Handbook of historical linguistics. Oxford: Blackwell, 2003. p. 575-601. https://doi.org/10.1002/9780470756393.ch18

HEINE, B.; CLAUDI, U.; HÜNNEMEYER, F. Grammaticalization: a conceptual framework. Chicago: The University of Chicago, 1991.

HENGEVELD, K. A hierarchical approach to grammaticalization. In: HENGEVELD, K.; NARROG, H.; OLBERTZ, H. (Ed.) The grammaticalization of tense, aspect, modality and evidentiality from a functional perspective (Trends in Linguistics). Berlin: de Gruyter Mouton, 2017.

HENGEVELD, K. Illocution, Mood and Modality. In: BOOIJ, G.; LEHMANN, C.; MUGDAN, J. (Ed.). Morphology. A handbook on inflection and word formation. Berlin: Mouton de Gruyter, 2004. v. 2, p. 1190-1201.

HENGEVELD, K. The grammaticalization of tense and aspect. In: NARROG, H.; HEINE, B. (Ed.). The handbook of grammaticalization. New York: Oxford University Press, 2011. p.577-591. https://doi. org/10.1093/oxfordhb/9780199586783.013.0047

HENGEVELD, K.; HATTNHER, M. M. D. The grammaticalization of modal verbs in Brazilian Portuguese: a synchronic approach. Journal of Portuguese Linguistics, Lisboa, v.15, p.1.-14, 2016.

HENGEVELD, K.; MACKENZIE, J. L. Functional Discourse grammar: a typologically-based theory of language structure. Oxford: University Press, 2008. https://doi.org/10.1093/acprof:oso/9780199278107.001.0001

HOFFNAGEL, J. C. A modalização epistêmica no processamento textual da fala. In: KOCH, I. G.V.; BARROS, K.S.M. (Org.). Tópicos em linguística do texto e análise da conversação. Natal: EDUFRN, 1997.

HOPPER, P. J.; TRAUGOTT, E. C. Grammaticalization. Cambridge: Cambridge University Press, 2003. https://doi.org/10.1017/CBO9781139165525

KEIZER, E. The lexical-grammatical dichotomy in functional discourse grammar. Alfa, São Paulo, v. 51, n. 2, p. 35-56, 2007. 
LOBATO, L. M. P. Os verbos auxiliares em português contemporâneo: critérios de auxiliaridade. In: . Análises linguísticas. Petrópolis: Vozes, 1975. p. 27-91.

MACIEL, J. W. G. Construções lexicais complexas constituídas com o verbo dar: processos metafóricos de construção de sentidos. 2005. Tese (Doutorado) - Universidade Federal da Paraíba, João Pessoa, 2005.

MIRANDA, N. S. A configuração das arenas comunicativas no discurso institucional: professores versus professores. 196f. Tese (Doutorado em Educação) - Universidade Federal de Minas Gerais, Belo Horizonte, 2000 .

NIKOLAS, G. PATTEN, A. Construction grammar and grammaticalization. In: HEINE, B.; NARROG, H. (Ed.). The Oxford handbook of grammaticalization. Oxford: Oxford University Press, 2011. p. 92-103.

NOONAN, M. Complementation. In: SHOPEN, T. (Ed.). Language typology and syntactic description. Cambridge: Cambridge University Press, 1985. p. 42-139.

OLBERTZ, H. Lexical auxiliaries in Spanish: How and why? Linguistics, 2016; v.54, 5, p. 947-979, 2016. https://doi.org/10.1515/9783110820881

OLBERTZ, H. Verbal periphares in a Functional Grammar of Spanish. Berlin; New York: Mouton de Gruyter, 1998.

PALMER, F. R. Mood and modality. Cambridge: Cambridge University Press, 1986.

PEZATTI, E. G. Um novo olhar para uma velha questão: ordenação de constituintes e a expressão de tópico, foco e contraste em português. In: FURTADO DA CUNHA, M. A. A gramática da oração: diferentes olhares. Natal: EDUFRN, 2015. p. 69-100.

PONTES, E. S. L. O tópico no português do Brasil. Campinas: Pontes, 1987.

RANGEL, C. A. L. Descrição de estruturas do tipo Dar N1 em N2 para o processamento automático de linguagem natural. 2012. Dissertação (Mestrado Acadêmico em Linguística), Universidade Federal do Espírito Santo, Vitória, 2012. 
SALOMÃO, M. M. M. Construções modais com dar no português do Brasil: metáfora, uso e gramática. Revista de Estudos da Linguagem, Belo Horizonte, v. 16, n. 1, p. 83-115, jan./jun. 2008. https://doi. org/10.17851/2237-2083.16.1.83-115

SCHER, A. P. As construções com o verbo leve "dar" e nominalizações em -ada no português do Brasil. 2004. Tese (Doutorado) - Instituto de Estudos da Linguagem, Universidade Estadual de Campinas, Campinas, 2004.

SOUZA, E. R. F. Gramaticalização dos itens linguísticos assim, já e aí no português brasileiro: um estudo sob a perspectiva da gramática discursivo-funcional. 2009. 273f. Tese (Doutorado em Linguística) Instituto de Estudos da Linguagem, Universidade Estadual de Campinas, Campinas, 2009.

TAYLOR, J. R. Linguistic categorization. Prototypes in Linguistic Theoric. $2^{\text {nd }}$. ed. Oxford: Claredon Press, 1995.

TRAUGOTT, E. C. Grammaticalization, constructions and the incremental development of language: Suggestions from the development of degree modifiers in English. In: ECKARDT, R.; JÄGER, G.; VEENSTRA, T. (Ed.). Variation, selection, development-probing the evolutionary model of language change. Berlin; New York: Mouton de Gruyter, 2008. p. 219-250.

TRAUGOTT, E. C. (Inter)subjectivity and (inter)subjectification: a reassessment. In: Subjectification, intersubjectification and grammaticalization. DAVIDSE, K.; VANDELANOTTE, L.; CUYCKENS, H. (Ed.). Topics in English Linguistics. Berlin/New York: Walter de Gruyter, 2010. v. 66.

TRAUGOTT, E. C.; DASHER, R. B. Regularity in semantic change. Cambridge: Cambridge University Press, 2002.

TRAUGOTT, E. C.; HEINE, B. (Org.). Approaches to grammaticalization. Amsterdam: John Benjamins, 1991. v. 1: https://doi.org/10.1075/tsl.19.1 / v. 2: https://doi.org/10.1075/ts1.19.2

VELLOSO, M. A emergência da gramática: estudo da idiomatização da construção modal com "dar" no Português do Brasil. 2007. Dissertação (Mestrado em Letras) - Universidade Federal de Juiz de Fora, Juiz de Fora/MG, 2007. 